\title{
Normal Deviants and Erving Goffman: Extending the Literature on Organizational Stigma
}

\section{Tommy Jensen}

Professor, Stockholm Business School, Stockholm University, Sweden

I Johan Sandström'

Professor, Industrial Environmental Management, Lulea University of Technology, Sweden

\begin{abstract}
The paper highlights two problematic tendencies in the burgeoning literature on organizational stigma. The first tendency is conceptual, where stigma is treated at the organizational level, thereby neglecting social encounters at the micro-level. As a way of remedying this, we enroll the seminal writings of Erving Goffman to situate organizational stigma in the interaction order. The second tendency is empirical, where the inclusion of actors performing stigma management is limited to managerial and organizational actors, thus neglecting many of those faced with managing organizational stigma. We report from an explorative study of ordinary wage laborers in the Swedish arms and pornography industries situated toward the bottom of their organizations and referred to as 'normal deviants'. The paper shows how and why the organizational stigma literature could be more sensitive and inclusive toward whom, how, when, and where organizational stigma is managed.
\end{abstract}

\section{KEY WORDS}

Arms / Goffman / normal deviant / organizational stigma / pornography / stigma transfer

DOI

10.19154/njwls.v5i4.4847

\section{Introduction}

rganizational stigma is a nascent and bourgeoning field of research in organization and work-life studies (Carberry and King 2012; Devers et al. 2009; Hudson 2008;

Mishina and Devers 2012; Vergne 2012). Asserting the construct, organizational stigma has been set against and separated from other related concepts in organization theory, such as organizational status (Devers et al. 2009), organizational misconduct (Pozner 2008), and organizational reputation (Devers et al. 2009; Mishina and Devers 2012). However, this emergent field's main critique of organization theory is its overdependence on legitimacy and that " other-than" legitimacy processes' are not considered (Hudson 2008, p. 252). A counterconcept, illegitimacy, has therefore been used to overcome this problem.

According to the organizational stigma literature, it is generally assumed within organization studies that illegitimacy is not only possible to overcome, but that a

\footnotetext{
${ }^{1}$ Corresponding author: johan.sandstrom@ltu.se
} 
crossover from illegitimate to legitimate is necessary for organizational survival (Hudson 2008; Devers et al. 2009). While such a crossover is possible for organizations suffering from what Hudson (2008) calls an event stigma, i.e., a temporary discrediting (cf. Pozner 2008; Sutton and Callahan 1987; Warren 2007), this is not the case for organizations that parts of society, based on the organizations' core products, routines, or customers (Hudson 2008), view as 'deeply discrediting' (Goffman 1963, p. 13). Rather, they suffer from what Hudson refers to as a core stigma, 'a strong or extreme form of illegitimacy' (2008, p. 252).

Compared to an organization suffering from event stigma, a core stigma organization can count less on the temporal aspect (e.g., that norms and values in society will change so as to render its business acceptable) and on opportunities to eliminate elements that discredit the organization (e.g., a corrupt executive, child labor, etc.). Such organizations include global arms companies (Vergne 2012), mixed martial arts organizations (Helms and Patterson 2014), men's bathhouses (Hudson and Okhuysen 2009), and AIDS service organizations (Cain 1994). Hudson also clarifies that this emerging field of research strives 'to understand organizations that do not, and cannot, achieve broad-based social acceptance' and 'yet are able to survive and thrive' (2008, p. 252). Consequently, the organizational stigma literature not only highlights organizations that are generally neglected in organization studies, but also what is often assumed to be impossible, enduring illegitimacy.

Although an emerging field, there are two problematic tendencies in the organizational stigma literature to date, one of which conceptual and the other empirical. The purpose of this paper is to highlight and examine these two tendencies. First, there is a conceptual tendency to move from stigma based on society's norms and values, e.g., as performed in social encounters (as in Goffman's interaction order) to stigma based on society's norms and values and as performed at the organizational level in 'organizational encounters.' We argue that this movement risks decontextualizing and deindividuating how organizational stigma is produced and managed in practice. In order to remedy this, we want to analytically highlight individual narratives and the level of the interaction order (Goffman 1959; 1961; 1963; 1967).

Second, and tentatively a consequence of the conceptual tendency, there is an empirical tendency to a priori decide which organizational members and stakeholders should shoulder the task of and bear the risk of managing organizational stigma. Here the organizational stigma literature reflects a general bias in organization studies to empirically remain at an organizational level by focusing on management or those directly involved in core processes, thereby neglecting workers at the lower and middle hierarchical levels. However, as Hudson (2008) and Hudson and Okhuysen (2009) emphasize, the reason for examining core stigma organizations in the first place is that a scientific discipline cannot neglect significant parts of what is out there in the field (e.g., organizations involved in industries such as alcohol, arms, nuclear, pornography, and tobacco) simply because they do not fit established theories or are illegitimate according to some social audiences (cf. Jensen and Sandström 2009; Rehn 2006). We argue that the same scientific argument is valid for criticizing the empirical tendency to neglect the majority of those working for core stigma organizations and who, tentatively, have to conceal, transform, or resist the organizational stigma. Therefore, the empirical material presented in this paper draws from an exploratory study of ordinary wage laborers (clerical officers, bookkeepers, assemblers, fitters, etc.) in the arms and pornography industries 
who are not situated at the center or top of their organization (addressing the empirical tendency). As we allude to in the title, we refer to these laborers as 'normal deviants' (Goffman 1963).

Next, we detail the conceptual tendency and our suggestion of how to conceptually develop the current literature. A research method section detailing the empirical tendency and our explorative study follows this. Thereafter we present the main findings drawn from the empirical material. The paper ends with conclusions and a discussion.

\section{Conceptually extending organizational stigma}

Mishina and Devers observe that stigma has often been treated as the organizational equivalent of individual stigma, but that conceptual efforts at 'delineating the differences between the individual- and organizational-level stigmas' (2012, p. 202) have emerged (e.g., the seminal articles by Hudson 2008, and Devers et al. 2009). Acknowledging that conceptual distinctions between individuals and organizations are made, analytically these distinctions still remain distinct. Organizational stigma analyses are not performed at the level of interaction order. For instance, Devers et al. (2009) claim that it is easier for an organization to avoid stigmatization than it is for a person working for such an organization, which implies a referral to a number of individuals making a collective effort to manage stigma. There is thus a strong reliance on the ability of human collectives to orchestrate joint efforts to conceal, transform, or resist stigma. In other words, there is a reliance on the formation of collective group identity (see Alvesson and Willmott 2002; Fleming and Spicer 2007; Kunda 1992).

When explicitly motivated, the focus on the organizational level is claimed to be necessary because the consequences for individual organizational members and external partners are already known (Mishina and Devers 2012) and because there is a need to develop knowledge about the consequences for organizations (Devers et al. 2009). What is often assumed is that those working for the organization show, or should show, value congruence or change their place of work (Devers et al. 2009). Hudson (2008, p. 261) also states that: 'As core stigma increases, insiders who are ambivalently identified with the organization and its values are more likely to leave. [...] The increase in personal identification is likely to mobilize insiders to directly challenge stigmatizing audiences.' Paetzold et al. (2008, p. 192) claim that organizational stigma 'motivates individuals to come together.'

The organizational stigma literature places further emphasis on organizational relations in terms of with whom or what the organization engages. Different names are given to these others, e.g., 'network partners' (Hudson 2008), 'external partners' (Hudson and Okhuysen 2009), and 'social audiences' (Helms and Patterson 2014). This leads to an increased focus on organization-level strategies to conceal, transform, or resist the stigma (Hudson 2008). Vergne's (2012, p. 1027) study of the global arms industry shows 'how managers can modify categorical associations at the industry and customer levels to decrease disapproval.' Helms and Patterson's (2014) study of mixed martial arts organizations shows 'the positive implications that stigma has for organizations and how it may lead to broader acceptance for them among social audiences.' Hudson and Okhuysen's study of men's bathhouses shows how these organizations use boundary management strategies to reduce the 'stigma transfer to network partners considered organizational outsiders' (2009, p. 148), while Cain's (1994, p. 45) study of AIDS 
service organizations shows how they develop organizational-level strategies that 'carefully manage its public image as a way of dealing with HIV-related stigma.'

So far the emerging field of organizational stigma has predominantly focused on the organizational level and the relations with some of the organization's external stakeholders. We argue that this field would benefit from a conceptual extension by a more encompassing use of an already widely cited source within the field-the sociologist Erving Goffman.

The reference to Goffman's book Stigma (1963) is a common denominator in the organizational stigma literature, although the use of Goffman has predominantly been definitional (what is stigma and how it can be translated from the individual to the organizational level) and not epistemological (how stigma is socially constructed but individually experienced). Authors usually refer to Goffman's definition of stigma as an 'attribute that is deeply discrediting' (1963, p. 13) and then cite Goffman's conditions (body, character, and/or category) leading to stigma (cf. Devers et al. 2009, p. 157; see also Helms and Patterson 2014; Hudson 2008, p. 254; Paetzold et al. 2008, p. 186; Vergne 2012). In this paper, extending the field of organizational stigma implies both a definitional and an epistemological use of Goffman's 'canonical understanding' of stigma (Paetzold et al. 2008, p. 186).

Goffman claims that everyone in society is discreditable and potentially has to manage stigma in order to avoid being discredited, 'a process occurring wherever there are identity norms' (1963, p. 155). This process is enacted by individuals in social encounters in the light of societal identity norms and values. In this paper, we do not engage explicitly with Goffman's identity discourse in relation to stigma (asking the 'who am I' question; if stigma management reveals a person's identity or not), but focus on 'situation management'-how individuals manage stigma (stigma management) —as the practical side of Goffman's stigma theory.

When we refer to organizational stigma in this paper we imply stigma associated with a particular category of organizations (core stigma organizations) that is transferred to a group of people or single individuals (within or outside of the organization) who have to conceal, transform, or resist this stigma transfer in social encounters.

Goffman (1959) laid the dramaturgical framework for his later analysis of stigma management using his widely spread concept of 'impression management' (for instance, in institutional theory). Impression management is performed in social encounters by us all, but stigma management (as an 'arts of impression management'; Goffman 1963, p. 155) is more of a concern when individuals who are 'deeply discredited' are involved. In other words, in such situations there is a greater risk of embarrassment or demands to conceal, transform, or resist stigma.

Goffman is basically interested in all types of social encounters, and particularly those that are quick and superficial and 'pertains mainly public life, to contact between strangers or mere acquaintances' (1963, p. 69). The reason is that such encounters are especially vulnerable to stereotypes and the " "profiling" of our normative expectations regarding conduct and character' (Goffman 1963, p. 68). Following Goffman thus implies that stigma and stigma management are not isolated, constant, or confined to a particular social setting, such as a workplace or an organization. This must be, as stated by Mishina and Devers (2012), an empirical question.

In a dramaturgical vein, Goffman outlines a conceptual armory with which to address stigma in all spheres of social life. He alerts us to the own, the wise, and the 
normal. The own are those who suffer from stigma transfer, such as colleagues at and suppliers of a core stigma organization. The wise are people who do not suffer from stigma transfer, but whose 'special situation has made them intimately privy to the secret life of the stigmatized individual and sympathetic with it' (Goffman 1963, p. 41). The wise can be close friends, family, experts, or other people who know the person in question and about his or her stigma. Or, as Burns puts it, the wise are 'on the social boundary between stigma and normality' (1992, ch 8, sec III) and are also those who are perhaps most vulnerable to what Goffman (1963) calls a courtesy stigma. An example from the organizational stigma literature of using one of Goffman's concepts at the organizational level is Helms and Patterson's (2014) translation of the wise to 'wise audiences' as 'non-stigmatized collectives.' There are also those who Goffman refers to as the normal, 'those who do not depart negatively from the particular expectations at issue' $(1963$, p. 15). This is obviously a broad category which, beyond strangers and superficial acquaintances, can also potentially include family and friends.

From the view of the stigmatics, there is also what Goffman refers to as front regions, where people risk being 'held morally accountable for their activities by other individuals who may actively or potentially disapprove of those activities, and hence, of the person performing them' (Dick 2005, p. 1373). In contrast, there is the back region, 'where the suppressed facts make an appearance' (Goffman 1959, p. 112) and people can relax. Front region situations are characterized by what Goffman calls mixed contacts, "the moments when stigmatized and normal are in the same "social situation", (1963, p. 23), where the stigmatics have to be tactful in order to avoid 'causing oneself or others embarrassment' (Goffman 1967, p. 103; 1959).

Goffman states that as long as the stigma is concealed in front regions with mixed contacts the person can remain discreditable and manage information, but that if the stigma is in the open the person risks being discredited and would then have to manage the associated tensions (Goffman 1963, pp. 79, 83). Here, Goffman highlights several strategies that individuals, alone or in teams, use when concealing and revealing the stigma and when managing it once it has been revealed (cf. 1963, pp. 113-128, 158-160), although he does not attach these strategies to a particular person or situation.

Stigma management strategies have formed a major part of the organizational stigma literature. However, as Meisenbach (2010) claims, such efforts have added or modified categories to certain sets of strategies, rather than focused on the notion that 'multiple and potentially contradictory strategies' (Meisenbach 2010, p. 288) are used when deciding: 'To display or not to display; to tell or not to tell; to let on or not to let on; to lie or not to lie; and in each case, to whom, how, when, and where' (Goffman 1963, p. 57). As Burns states: 'There simply are no widely observed conventions for encounters between stigmatics and normal' (1992, ch 8, sec III), or to quote Goffman: 'These problems cannot always be handled by past experience, since new contingencies always arise, making former concealing devices inadequate' (1963, p. 110).

Armed with these concepts, Goffman helps to reveal the fragility and temporary constitution of what might appear to be a stable interaction order and, we consequently argue, that this is also the case for organizational stigma. The key to Goffman's conceptualization of stigma is the constant tension between routine and crisis (Hughes 1994), ritualization and vulnerability (Persson 2012), or containment and havoc: 
Without self-control, without containment of our emotions, psychological states, and actions, 'society' would no longer function. A society without containment is a society (or the multiplicity of situations that comprise a society) of havoc, one that has become unpredictable or unmanageable from the point of view of one or possibly even all participants (Hancock and Garner 2011, p. 321).

Containment at the level of the interaction order is thus linked to macro-order problems, but there is of course a linkage between the interaction order and organizations (Hacking 2004). Regarding the organizational stigma literature, there is a significant potential to better acknowledge this linkage between the interaction order and the organization. If situations are not contained and therefore break down, 'disruptions to the normative order create (organizational) havoc for everyone' (Hancock and Garner 2011 , p. 323) in both a positive and negative sense. By following Goffman (1963), questions of to whom, how, when, and where organizational stigma is contained and when havoc is caused can be addressed.

\section{Research method}

According to Meisenbach (2010), the highly contextual nature of stigma calls for research that widens the scope of which individuals and groups of individuals are at risk of being stigmatized. In this paper we propose such a widening by focusing on wage laborers who are not situated at the center or top of a core stigma organization.

In terms of the work they do, the workers targeted in this study are not publicly exposed to the same extent as a top manager might be. Nor do they work explicitly with core operations, as a porn actor or a ballistic engineer does. They could be clerical officers, bookkeepers, salespersons, someone managing the inventory, or making sure that the administrative machinery runs smoothly. They might be industrial laborers, those assembling products, mechanics, fitters, or someone who makes sure that the production process runs smoothly. Laborers like this probably constitute the majority of the people working in core stigma organizations. If they were to be removed (like the customers, suppliers, and regulators in Hudson and Okhuysen's study), core stigma organizations would probably not survive.

These workers do not emit any social information, 'the information the individual directly conveys of himself' (Goffman 1963, p. 10), that associates them with a work-related stigma. They do not seem to need what Goffman calls 'disidentifiers' (1963, p. 60) or 'prestige symbols' (1963, p. 59), because they predominantly internalize the knowledge about their work-related stigma. There are no explicit 'stigma symbols' (Goffman 1963, p. 59, italics in original) to reveal them. An interviewee working for a porn company told us that in encounters with strangers it is possible to get away with telling a lie, for example, that 'I work as a preschool teacher.' An apt Goffmanian term for these laborers is 'normal deviants' (Goffman 1963).

Further, we argue that wage laborers who are not situated at the center or top of a core stigma organization 'tend to have less commitment and emotional attachment to the organization [---]. They have jobs, not careers' (Goffman 1961, p. 201). This might suggest that they do not need to worry too much about organizational stigma, because to them it 
is just a job. Following Goffman, and contrary to what is assumed in previous research, value congruence with the organization does not have to be a major issue, but is difficult to know a priori.

This group of people has been neglected in previous research. Helms and Patterson (2014) mention that they interviewed 'administrative employees for MMA organizations,' while Hudson and Okhuysen (2009, p. 138) list that they interviewed five 'workers' (no more information is given). Hudson and Okhuysen (2009, p. 148) state that they 'found that customers, suppliers, and regulators can suffer by their association with a bathhouse,' but there are weak traces of organizational employees, particularly the type of workers targeted in this paper, in previous research on core stigma organizations. Overall, they are peripheral when the empirical material is presented and absent when analyses are made.

The context of the workers explored in this paper is the arms and pornography industries. Workers from these industries have been chosen because it is reasonable to assume that they face strong societal resistance, at least in the Swedish context (the overall context of the empirical study). We know this from Swedish media reports of these industries, from the use of secondary material in Swedish, such as expert reports (predominantly on arms) and scholarly material (predominantly gender and the porn industry), and from simply being part of a society in which mentioning arms or porn often upsets people and in which heated and stereotyping debates about these industries regularly occur.

Our reading of the organizational stigma literature prompts us to provide evidence of existing organizational stigma by measuring its strength or force (see, e.g., Devers et al. 2009; Hudson and Okhuysen 2009; Mishina and Devers 2012; Vergne 2012; who all call for better ways of measuring organizational stigma). However, having said that, the literature on organizational stigma does not view stigma as a static phenomenon. Stigma, it is claimed, is contestable and has to be negotiated in social contexts. This creates a caveat for Hudson's (2008) concept of core organizational stigma, because it implies something that is objective, distinct, and enduring. If we have interpreted the meaning that Hudson (2008) attaches to the concept correctly (strong stigma associated with organizations' core activities), he does not rule out that an organization or industry can suffer from pre-existing stigma (Devers et al. 2009) and that stigma is contextual and can change depending on the context. As Vergne (2012) also points out, an organization belonging to a stigmatized category of organizations does not necessarily have to experience disapproval from different stakeholders.

By enrolling Goffman, the interaction order is seen as being more complex than is accounted for in the organizational stigma literature, in that stigma is constantly enacted in all areas of life and is therefore not easy to define and measure. An option is therefore to empirically explore whether or not people working for these organizations experience a stigma transfer (Sutton and Callahan 1987). Meisenbach (2010) also calls for studies that abandon 'certain a priori, objectively observable characteristics' (p. 271), particularly assumptions that 'the stigma is perceived and determined by the non-stigmatized individual' (p. 270), and instead investigate 'individuals perceptions of themselves' (p. 271).

In this study, interviews with ten different workers (five from two small porn companies and five from one large arms company) constitute the main empirical material. Each worker was interviewed twice with about a three to six months interval between the interviews, making the total number of interviews twenty. All the interviews were 
taped and transcribed. Mainly for contextual reasons (and not subject to a more careful analysis), a lot of other empirical material was also gathered (physical visits to workplaces, product catalogues, websites, etc.). The focus of this paper is on the conversations with workers. At the arms company we interviewed a market communicator (A1), an IT systems administrator (A2), an assembler (A3), a senior communicator (A4), and a senior market manager (A5). A1 is female and the rest are male. A4 and A5 are closer to the core operations than the other three. At the first porn company we interviewed two women (P1 and P2) working in the office with bookkeeping and sales support. At the second porn company we interviewed two women (P3 and P4) working with bookkeeping, sales support, and editorial tasks, and a man (P5) working with purchasing.

Due to a previous research project including a large company in the arms industry, access to workers proved easy and we had some discretion in the choices of who to talk to. In the main the target of a diverse set of 'normal deviant laborers' was achieved. Setting up the porn study proved to be more challenging. These companies are not as visible as, for example, a large arms company. There are no large porn companies in Sweden, but some smaller ones. Cold calls to a handful of companies identified on the Internet resulted in failure, whereas two companies (with less than 15 permanent employees) eventually provided interviewees. In these cases, basically no discretion in the choice of interviewees was possible, and although less diversity in terms of roles and tasks was achieved, access to 'normal deviant laborers' was granted.

The script for the interviews is based on Goffman (1963) and Ashforth et al. (2007; see Appendix), drawing explicitly on Goffman's dramaturgical setting and key concepts such as own, wise, and normal. The participants were encouraged to elaborate on their work in relation to the stigma transfer in all areas of life, as whole persons and not just as workers, both before joining the company and during their employment. Although the empirical material is limited, it enables us to provide a critical case (Flyvbjerg 2006) in relation to the conceptual and empirical tendencies in the organizational stigma literature.

On processing the interviews, the first observation is that all the interviewees have their own unique stories to tell about stigma transfer from the organization. As Goffman (1963) also claims, stigma is conditioned by society's identity values, but these values are not simply diffused from the macro- to the micro-level. Social values influence individuals and social encounters, but never determine or define (Klinton 2014; Young 1994) the interaction order. So, even though we anticipated that stigma could be a problem for the workers, in that they might find it difficult to escape the marks of an organizational stigma, it does not imply that it determines how the stigma marks the individual's life (Young 1994, p. 734).

The conducted research underpinning this paper is guided by dialogical conversations from which stories about working life are crafted (Czarniawska 1997; 1999). Hence, in this study, the workers were selected and included for analytical rather than empirical reasons, meaning that they are not meant to be a numerical or statistical sample representing a population or a category that is established through the establishment of more or less rigorous theoretical definitions. The empirical material serves as a critique and extension of the literature on organizational stigma. In the empirical section below, we highlight what we see as the three main stories related to how the workers face and manage the stigma transfer from their organization. These stories emerge from a coding process where we zoom in on all the occasions the interviewees relate to stigma 
management (toward whom, how, when, and where), rendering a gross list of sections of the interviews best referred to as a first-order coding. These sections were further analyzed by searching for common rationales, or what Van Maanen (1979) calls secondorder themes, rendering three salient stigma management stories.

The first story, which emerges during the analysis of the first round of interviews, is about (i) workers clearly facing stereotypes that expose them to the risk of being stigmatized. The second story, which also emerges in the analysis of the first round, is that (ii) the management of stigma has to be performed in all areas of life. These two stories were to some extent anticipated beforehand, given the Goffmanian framing of the project, but the third story was less so. It is common in the stigma literature to distinguish groups of stigmatics and view them as collectives that together craft ways of concealing, transforming, and resisting stigma. Goffman also seems to endorse such a view to some extent. The third story to emerge is about (iii) a lack of group-like collectives among the workers.

\section{The empirical study}

\section{(i) Workers facing stereotypes}

Concerning the question of whether or not there is a risk of stigma transfer, all the interviewees reveal a strong awareness of this: 'People think that we are sitting here oppressing women' and 'If I tell that it is porn movies, then the whole package hits me' (P3), 'People's imaginations run amok' (P4), 'It's hard to defend, it's basically about laying low' (P5), 'It is a very controversial industry to work for' (A1), and 'working for this organization you are already from the beginning questioned' (A4). In short, stereotypes abound. The interviewees view themselves as guilty by association, regarded as 'coldhearted' and 'callous' (A4), 'I have had "you are a gun dealer" thrown right in my face' (A1), 'a very, well, sexual being, very over-sexual, or stupid, that is, unintelligent' and 'rich, you have cash' (P1). As P3 puts it: 'I want them to judge me because of who I am and not because of what I do. But most often, since it is this kind of industry, you are associated in ways that you don't want to be.'

Thus, the transfer of organizational stigma becomes difficult to manage for these workers. It is also clear that, due to the risks involved, most of the interviewees are very reluctant to reveal where they work, despite having few examples of such revelations getting them into trouble, hence our reference to these workers as normal deviants.

However, stereotypes and prejudices exist on both sides. According to P3: 'Those who are most critical are those who are the largest consumers,' 'But if you talk to a man, for example, it is quite easy. Men prefer to talk about themselves, then you only have to pay attention to the man's interest,' and 'They think that women are humiliated, but the fact is that in the porn industry women earn most money.' All the interviewees from the arms company expressed that boys are more interested in weapons than girls: 'My oldest son thinks that weapons are a bit cool; he's at that age right now' (A2), and A4 mentions his daughter's boyfriend who wanted to bring his friends to the factory to see how weapons are made. A1, seemingly without reflecting on it, calls those opposing the arms industry 'hippies,' while P1 uses the label 'feminist' to refer to those opposing the porn industry (a label she was not comfortable with, but that she thought reflected how they talked about the more radical opponents of the industry). 
P5 also states that: 'You can read what kind of person they are. [---] If it is a construction worker, then you know that it is no problem' and that 'I think the younger generation that is now growing up, they accept this [the porn industry] more readily than the older generation.' P2 says that she does not think that older people would be comfortable with the industry she works for. P1 also reveals during the second interview that when one of us called the company in the search for interviewees for this study and she heard a man's voice, she thought 'oh no, not another one who wants to be a porn star.'

The first story can be summarized as follows: The workers frame the social world by using stereotypes and prejudices, but they are explicit that others' use of stereotypes and prejudices on them is utterly misleading and unfair.

\section{(ii) Stigma management in all areas of life}

Despite their unique stories, when targeting Goffman's questions of to whom, how, when, and where the stigma is concealed, transformed, and resisted more carefully, the workers seem to live through and share certain experiences and perceptions. From these experiences and perceptions two overall observations about their stigma management can be identified. First, A1's situation is illustrative (our emphasis): 'I would rather not talk to my children about what I work with,' 'We [she and her friends] avoid talking about work, or I avoid it, because I know that it could end our friendship,' 'I feel that my parents have a problem with it [...] that their daughter is an arms dealer,' 'we [with her husband] never discuss the ethical question,' [at a party] 'I would try to stay away.' A2 describes how his wife has been confronted with comments like 'how can she be married to a man who makes weapons,' but that 'she is very comfortable with this.' Or as told by P3:

At midsummer I was with my old friends. [---] We celebrated with [one of her friend's] brother and his family. But there I felt, we did not talk about work at all. But then they came a couple of days later and they started to talk about [the company where she works]. [---] They had been drinking and then, it was something about sex toys, but I had not mentioned where I work and [her friend] and I started to laugh. [---] Then I could-oh my god I work there-and then in a way it became natural [to tell], and they thought it was fun and cool. Otherwise, I would never have revealed it. It is basically just close family that knows where I work.

P5 says that: 'He [his son] doesn't ask, but he knows basically everything. [---] We talk about it as any job, no deeper discussions about it.' P1 reveals that it took a long time for her to tell her boyfriend what type of company she worked for.

For the workers that we talked to the stigma transfer penetrates social encounters in all areas of life. The workplace seemingly emerges as a back region where the worker can relax, although this can quickly change. A telephone call from the preschool or school (as P1, P2, and P3 mention) to the wrong number can reveal their place of work. The home is also tentatively a back region, although as shown, close family and friends are sometimes not aware of their place of work. It is often the case that those who know and sympathize feel the need to protect the wise and the normal from courtesy stigma, although stigma management is also sometimes required by the wise. 
P3 talks about her daughter: 'When she went to school, I didn't want her to .... I didn't tell her to lie, but I said that you perhaps don't have to talk about ... mummy's work.' However, once her daughter's schoolmates and their parents found out where she worked the news soon spread on the social media. 'She has never had any problems with it [where she works] before, but ever since then she lies about where I work.' A2 says that: 'I told the kids that this is not something that you need to talk specifically about, that I work for [the company's name].' P4 says that she will not reveal where she works to older people and that 'I do this out of concern for them, they wouldn't understand. So it is more about concern.' A similar story comes from A1: 'I don't think my grandma [on her mother's side] knows what I work with, that is, which industry I work in. I don't think my mother would tell grandma, simply because it would be difficult to explain.'

All that is needed for a social situation to get out of control is a normal question (what do you work with?) and an abnormal answer (I work for a porn or arms company). Although these workers are not as visible as many of the actors included in previous research on organizational stigma, they always need to be prepared and have their social feelers out. Essentially, it adds a work-off work interface to organizational stigma studies and shows how organizational stigma has to be contained in all areas of life. The second story can be summarized as follows: Stigma transfer is a challenge in all areas of life for the workers, with a high risk of courtesy stigma to close friends and family, and seems to create a very limited back region where the workers can relax.

\section{(iii) A lack of group-like collectives}

Targeting the particular strategies the workers use, P1 illustrates a typical example from the interviews. She uses the phrases 'I'm an office worker' or 'I'm an administrator' and then hopes that the work-related part of the conversation is over. If not she switches to plan B, which is based on the Swedish company she works for being owned by a larger international group whose name is not known to the general public in Sweden. She can simply state this company's name and then hope that things are not taken further. Alternatively, she has sometimes used a rather innovative tactic, which is to claim that her employer is a 'wholesaler of plastic-film and prostheses.' Although this is not a lie, she tells us, it is not really the truth either. Certainly, different products sold by the company are made out of plastic: the Swedish for porn films is 'porrfilm' and dildos could be viewed as prostheses. P1 has abandoned this tactic because it is too complicated, but she is still selective about saying what her company does: 'So as to not tell an outright lie I say that we sell oils and health related products.'

P2 uses a similar strategy by saying 'I work in an office' and hopes that this is sufficient. When pressed she emphasizes that she works with tasks. This is done in a neutral way, in that she receives orders, registers new customers, customer service, etc. However, she once responded to her neighbor who insisted on knowing what her company was doing by saying, 'we sell porn, he became quiet and I haven't heard anything since.' But she admits that she has only used this confrontational style once. P4 states that: 'Children often ask what you do and I have never lied about that, because I do the numbers [accounting]. It is another thing if they ask what the company produces.'

A revealing example of the importance of a particular situation influencing the strategy used is when at a nightclub P3 said 'I work as a preschool teacher,' but then used 
a different strategy on her daughter. She has never told her daughter's teachers where she works and cannot use the preschool tactic because there they need to have her work telephone number to hand. 'I told them that I worked for a newspaper company [---] and it worked.' So, to all intents and purposes she is a preschool teacher at night and an editorial assistant during the day.

A3 makes use of the fact that most people do not know much about his type of work-assembling-and says that if 'they know more they might ask other questions. Then you have to explain what you do but when I have done that it has not led to any conflict about what I work with.' An important twist is that A3 uses technologically loaded jargon when talking about his work in order to steer the conversation away from the subject. If pushed further he 'closes the door' by saying that 'it is defence material for national security, to defend its territory, even for those customers that [we export to].' P5 says that 'If I have never met them before, I simply say that I work with supply management in a company. [---] I don't say anything more.'

A2 says that he 'continuously assesses what is and what is not talked about' and that he is especially careful when meeting a person (a 'normal' until proven otherwise) for the first time:

I never disclose where I am from when out travelling, you try to hide that as much as possible. That is, no stickers, and such. [---] You don't want to expose yourself for, for example, a terrorist. This is for precautionary reasons, because at the end of the day we manufacture guns that are used in Iraq. [---] But usually I say that I work with bombs [---], so that it will be quiet. [---] But just as with any conversation, you do a case-to-case judgement, and it has certainly happened that I have felt that it has not been appropriate to talk about it. Then I have avoided it.

The workers' experiences inform them that a situationally contingent approach is useful because it works. Emerging from their stories is a strategy that makes pre-planned stigma management scripts less useful ('continuously assesses,' 'case-to-case,' using what works). This strategy seems to work because the workers have developed a readability of people and situations and, based on the particular situation, can be tactful (Goffman 1959).

All the interviewees were asked whether they talked about stigmatization at work. They all said that this was not discussed. This reflects the situation off-work as well among the normal and the wise. In addition, the interviews do not contain strong narrations about engaging in discussions off-work concerning whether they and their work is discredited or discreditable or not. How they manage the stigma and their experiences of it are more or less individualized. In short, they have to deal with different situations and do not expect any explicit help from colleagues or managers (and seem to think that it is up to each of them to decide whether or not to work for a stigmatized company and that if there is a problem it is their problem). In this sense, the interviewees share similar experiences about how to manage the stigma transfer in practice, although their repertoires of strategies are rich, varied, and individual.

However, a typical approach is to keep quiet: to read the normal and the situation and steer the conversation away from work. Then, if anything needs to be said it can be as neutral and vague as possible (say what you do, state the parent company's name). If this does not resolve the matter, the remaining options are to lie (preschool teacher) or be open (I sell bombs, we sell porn).

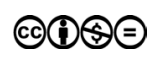


Despite the interviewees sharing their positive experiences of revealing where they work, and despite having had few negative first-hand experiences, their social feelers are constantly out. In the conversations we had with them there was a sense of weariness about this. The strong hesitation to reveal appears to be common in contact with the normal in social situations that are very close to what would presumably be back regions for these workers (at home, at work) and in those that are quick and superficial in 'public life' (Goffman 1963, p. 69). Revealing is usually not done unless there is no other option, i.e., when a person insists on an answer to the question about the workplace, which industry, and which organization, or when the 'situation' requires it and they can trust that revealing will not change the perception of who they are.

A final aspect of their stigma management is how the interviewees discursively articulate themselves in relation to how they act in order to manage the interaction order and the risk of being stigmatized. P5 says: 'You sort of gear the conversation away from the subject. [---] I don't think about it anymore, it is automatic, these days. [---] It has turned into a habit.' P4 says that she always think tactically, 'in any case,' but continues by saying 'I do this unconsciously. [---] If I sense that I don't have to tell, because they would not understand [---] I could choose to [tell], I could start a fierce discussion, but I choose not to':

Unconsciously it is that way. [---] You sort of notice which group of people that ... there are groups of people that, I mean, they just gasp, but take it as it is. But there are groups of people that just want to turn their back on you, or want to taunt you. You feel it if you are about to be drawn into such a situation, then, without choosing you chose, actually.

\section{A3 thinks that it is:}

Gut feeling. Or sense, you feel the vibes. Is this the right time or not? Sometimes I get it right and sometimes I get it wrong, but I have never had to engage in a discussion about why I work with guns. [---] You can see it in [their] actions. Not that [they] verbally say something like 'I don't like this.' [---] They react, but not verbally.

Thus, when the workers are asked about how they perform stigma management, they cannot discursively articulate it, at least not in any precise way. They refer to a gut feeling, which they sense and see in people's actions. The workers have used stigma management strategies to such a degree that they have become embodied. By embodied we mean that mind and body are intertwined in a way that is not fully recognizable by the mind or the logic of discourse (Yakhlef 2010). It is simply 'what you know so well that you don't have to think about it to do it' (Becker 1998, p. 216). The third story can therefore be summarized as follows: How the workers manage the stigma transfer is varied, situationally contingent, individualized, and embodied.

\section{Discussion and conclusions}

What first emerges from the study is that the normal deviant laborers have a strong awareness of, and even a strong weariness about, the stigma transfer from the organization, the sometimes high stakes associated with this transfer, and that these risks exist in their everyday lives at and off-work and among strangers, family, and friends. The 
normal deviants' problem of engaging with the wise and normal suggests that they are vulnerable to 'the perpetually recurring possibility of ordinary, normal, members of society rejecting his claim to be one of them' (Burns 1992, ch 8, sec II). This, we suggest, is an important reason for the weariness displayed by the workers in this study.

Secondly, the normal deviants are also basically alone in their stigma management, which contradict previous research on organizational stigma. The workers in this study are not engaged in collective activities for the purpose of improving their capacities to conceal, transform, or resist the transfer of organizational stigma. Rather, the stigma management is individually performed. Being a wage laborer who is not situated at the center or top of a core stigma organization places strong demands on stigma management, often with little or no help or support from a collective of owns.

This challenges the commonly held belief in the organizational stigma literature that those suffering from stigma transfer develop a collective identity. Although there is in a sense an identifiable collective in terms of a group that suffers from the stigma transfer and has similar experiences in relation to this stigmatization, an important difference is that there is no ideology of a group or category of stigmatics and no representatives or spokespersons who can generate support and be the voice of the group. Their back region is thus surprisingly small (where they can relax and do not have to worry about the stigma transfer), despite sharing similar experiences and strategies with peers.

Thirdly, the narrative reveals that normal deviants adopt a sprawling stigma management, which means that they will use any strategy to get them out of the situation. Therefore, rather than developing a shared set of tactics, normal deviants develop individual tactics that are used as long as they work. In other words, this study suggests that there is a richness in terms of the kind of strategies that are used when performing stigma management (see also Goffman 1963).

These three observations give rise to an overarching conceptual conclusion. The paper shows that stigma related to organizations' core products, routines, or customers cannot simply be lifted to the organizational level without the risk of decontextualizing and deindividualizing how such stigma is socially constructed and how social encounters are managed by those suffering from it. Developing the organizational stigma literature's already frequent use of Goffman's writings on stigma to also include a more epistemological use can remedy this decontextualizing and deindividualizing trend in organizational stigma research. This study therefore challenges:

- a too rigid conceptual framing of who and what counts as stigmatized, as such a priori drawing of boundaries risks excluding the majority of those having to conceal, transform, and/or resist organizational stigma,

- a too rigid conceptual framing that assumes that a collective of persons will take shape in organizations, despite the difficulties, and that this will function as a buffer against stigmatization for the members of the collective,

- a too rigid focus on adding or modifying categories to certain sets of stigma management strategies (Meisenbach 2010), which could risk being too insensitive to a sprawling (varied, situationally contingent, individualized, and embodied) stigma management.

Turning to the particular group of stigmatics in this study, the paper also shows that wage laborers who are not situated at the center or top of a core stigma organization, i.e., normal deviant laborers without whom organizations would be unable to perform,

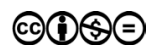


have a far too important role in core stigma organizations to be neglected by organizational stigma research. Core stigma organizations rely on normal deviants being able to manage the tension between containment and havoc (Hancock and Garner 2011) at the level of the interaction order (Goffman 1959; 1961; 1963; 1967).

\section{Implications}

Relevant to the relation between the interaction order and the organization, when normal deviants contain their emotions, psychological states, and actions (Hancock and Garner 2011) they seem unable to reflect on whether or not it is ethically justifiable to stay with the company. Similarly, they seem ethically unable to justify leaving the organization and whether they should persuade others to leave as well. It seems as though major areas of the worker's life world, for some also that of their spouses and children, are characterized by severe difficulties in engaging critically and ethically with the stigma associated with their work. A reason for this is that the deviant laborers seem to have a rather limited discursive consciousness, i.e., ability to put practical consciousness into words (Haugaard 2003).

However, we do not suggest that discursively well-developed ethical judgments are a safeguard against being discredited. Nor are we suggesting that a discursively welldeveloped ethical judgment is always reasonable. The trial of Otto Adolf Eichmann in Israel is a case in point. He was able to explain why he was a good bureaucrat as well as a good follower of Kantian ethics, but was condemned as a banal person representing the phenomena of the banality of evil (Arendt 1963/1994). What we do suggest is that ethical judgment is important as a way of easing the tensions for the workers, because a discursive consciousness (not the type of banal discursive consciousness that Arendt analytically revealed) enables them to participate in critical reflections on stigma in all areas of life, which is always socially contestable.

In other words, this question is not only relevant for how core stigma organizations can transform stigma, or how marginalized collectives and organizations can overcome stigmatization (as in Helms and Patterson 2014), but also for the question of the discursive consciousness of workers. Using Hirschman's (1970) vocabulary, the workers do not seem to be able to act through 'voice' and take an active part in collective organizational attempts to change the organization 'from within.'

\section{Future research}

In a development of this nascent and bourgeoning field of research, there is a need to more empirically explore the tension between how normal deviant laborers manage the fragile border between containment and havoc addressed above and how this is connected to macro-order problems (Hacking 2004; Hancock and Garner 2011). This micro-macro problem is essential because the normal deviants in this study work in a socially questionable context and their role and function in supporting this context is blurry. They are needed but exchangeable, and see their role and function in relation to their organizations' core business as indirect (I'm only a controller, not producing or selling weapons; I'm only an administrator, not a porn star or film maker). 
As Bauman informs us, most analyses of morally questionable actions and events separate 'the bystanders from the perpetrators no less radically than it set them apart from the victims' (2002, p. 201). Macro social problems (in our cases, for example, guns ending up in the wrong places, guns being used to kill innocent victims, trafficking victims forced to perform sex in front of the camera, underaged porn actors, etc.) are often explained through extraordinary circumstances, evil people, inherent greed, power-madness, whimsicality, and mass panicking. These explanations are enrolled to serve those who do not want to consider the idea that normal men and women, however distant they may appear from the core, play an essential part in enabling horrific actions and events. In this sense, Bauman $(1989 ; 2002)$ argues, the bystanders are essential in relation to perpetrators and victims (see also Jensen 2010).

Considering that normal deviants fill a bystander function makes us suspect that they are in an especially vulnerable position. They are part of what Young (1994) calls a serial collective, which seems to have weak discursive consciousness that makes it difficult for them to participate in critical reflections on ethical problems related to the core stigma organization. Studies on the dynamics of serial collectives suffering from organizational stigma and their relation to discursive consciousness are therefore needed.

Such collectives of normal deviant laborers might be found in other types of core stigma organizations, such as those related to alcohol, gambling, tobacco, and nuclear power. Importantly, this suggestion does not imply that differences and similarities between different core stigma organizations, industries, or contexts are teased out, but that the particular category of workers is explored more widely in terms of how stigma marks their lives, how it disables their discursive consciousness, why and how it enables core stigma organizations to continue contributing to macro-order problems.

To further such a direction in organizational stigma research, it would be rewarding to go beyond the research method used in this study, the interview set-up, and design a more ethnographic study, including not only the normal deviant laborers but also the owns and the wise.

\section{References}

Alvesson, M. and Willmott, H. (2002) 'Identity regulation as organizational control: Producing the appropriate individual', Journal of Management Studies 39(5): 619-644. doi: http://dx.doi.org/10.1111/1467-6486.00305.

Arendt, H. (1963/1994) Eichmann in Jerusalem: A Report on the Banality of Evil. New York: Penguin books.

Ashforth, B.E. and Kreiner, G.E. (1999) “"How can you do it?”: Dirty work and the challenge of constructing a positive identity', Academy of Management Review 24(3): 413-434. doi: http://dx.doi.org/10.2307/259134.

Ashforth, B.E. and Kreiner, G.E. (2014) 'Dirty work and dirtier work: Differences in countering physical, social, and moral stigma', Management and Organization Review 10(1): 81-108. doi: http://dx.doi.org/10.1111/more.12044.

Ashforth, B.E., Kreiner, G.E., Clark, M.A. and Fugate, M. (2007) 'Normalizing dirty work: Managerial tactics for countering occupational taint', Academy of Management Journal 50(1): 149-174. doi: http://dx.doi.org/10.5465/AMJ.2007.24162092.

Bauman, Z. (1989) Modernity and the Holocaust. Cambridge: Polity Press.

Bauman, Z. (2002) Society under Siege. Cambridge: Polity Press. 
Becker, H. (1998) Tricks of the Trade. How to Think about Your Research While You're Doing It. Chicago: The University of Chicago Press.

Burns, T. (1992) Erving Goffman [E-reader version]. London: Routledge.

Cain, R. (1994) 'Managing impressions of an AIDS service organization: Into the mainstream or out of the closet?', Qualitative Sociology 17(1): 43-61.

Carberry, E.J. and King, B.G. (2012) 'Defensive practice adoption in the face of organizational stigma: Impression management and the diffusion of stock option expensing', Journal of Management Studies 49(7): 1137-1167. doi: http://dx.doi.org/10.1111/j.14676486.2012.01075.x.

Czarniawska, B. (1997) Narrating the Organization. Dramas of Institutional Identity. Chicago: The University of Chicago Press.

Czarniawska, B. (1999) Writing Management. Organisation Theory as a Literary Genre. Oxford: Oxford University Press.

Devers, C.E., Dewett, T., Mishina, Y. and Belsito, C.A. (2009) 'A general theory of organizational stigma', Organization Science 20(1): 154-171. doi: http://dx.doi.org/10.1287/ orsc. 1080.0367.

Dick, P. (2005) 'Dirty work designations: How police officers account for their use of coercive force', Human Relations 58(11): 1363-1390.

Fleming, P. and Spicer, A. (2007) Contesting the Corporation. Cambridge, UK: Cambridge University Press.

Flyvbjerg, B. (2006) 'Five misunderstandings about case-study research', Qualitative Inquiry, 12(2), 219-245.

Goffman, E. (1959) The Presentation of Self in Everyday Life. New York: Anchor Books, Doubleday.

Goffman, E. (1961) Asylums. Essays on the Social Situation of Mental Patients and Other Inmates. New York: Anchor Books.

Goffman, E. (1963) Stigma. Notes on the Management of Spoiled Identity. Englewood Cliffs: Prentice-Hall.

Goffman, E. (1967) Interaction Ritual. Essays on Face-to-Face Behavior. New York: Pantheon Books.

Hacking, I. (2004) 'Between Michel Foucault and Erving Goffman: Between discourse in the abstract and face-to-face interaction', Economy \& Society 33(3): 277-302.

Hancock, B.H. and Garner, R. (2011) 'Towards a philosophy of containment: Reading Goffman in the $21^{\text {st }}$ century', American Sociologist 42: 316-340. doi: http://dx.doi. org/10.1007/s12108-011-9132-3.

Haugaard, M. (2003) 'Reflections on seven ways of creating power', European Journal of Social Theory 6(1): 87-113.

Helms, W. and Patterson, K. (2014) 'Eliciting acceptance for "illicit" organizations: The positive implications of stigma for MMA organizations', Academy of Management Journal 57(5): 1453-1484. doi: http://dx.doi.org/10.5465/amj.2012.0088.

Hirschman, A.O. (1970) Exit, Voice and Loyalty: Responses to Decline in Firms, Organizations and States. Cambridge, MA: Harvard University Press.

Hudson, B.A. (2008) 'Against all odds: A conceptualization of core-stigmatized organizations', Academy of Management Review 33(1): 252-266. doi: http://dx.doi.org/10.5465/ AMR.2008.27752775.

Hudson, B.A. and Okhuysen, G.A. (2009) 'Not with a ten-foot pole: Core stigma, stigma transfer, and improbable persistence of men's bathhouses', Organization Science 20(1): 134-153. doi: http://dx.doi.org/10.1287/orsc.1080.0368.

Hughes, E.C. (1994) On Work, Race, and the Sociological Imagination. Chicago: The University of Chicago Press. 
Jensen, T. (2010) 'Beyond good and evil: The adiaphoric company', Journal of Business Ethics 96(3): 425-434. doi: http://dx.doi.org/10.1007/s10551-010-0475-4.

Jensen, T. and Sandström, J. (2009) 'Global trafficking networks and business studies', Tamara Journal for Critical Organization Inquiry 7(4): 147-159.

Klinton, M. (2014) Det rationella och det normala-om lönearbetets logik, praktik och etik (The Rational and the Normal-on the Logic, Practice and Ethics of Wage Labour). Örebro: Örebro Studies in Business, Örebro University.

Kunda, G. (1992) Engineering Culture: Culture and Commitment in a High-Tech Corporation. Philadelphia: Temple University Press.

Meisenbach, R.J. (2010) 'Stigma management communication: A theory and agenda for applied research on how individuals manage moments of stigmatized identity', Journal of Applied Communication Research 38(3): 268-292.

Mishina, Y. and Devers, C.E. (2012) 'On being bad: Why stigma is not the same as a bad reputation', in M.L. Barnett and Pollock, T.G. (eds.) The Oxford Handbook of Corporate Reputation. Oxford: Oxford University Press, pp. 201-220.

Paetzold, R.L., Dipboye, R.L. and Elsbach, K.D. (2008) 'A new look at stigmatization in and of organizations', Academy of Management Review 33(1): 186-193. doi: http://dx.doi. org/10.5465/AMR.2008.27752576.

Persson, A. (2012) Ritualisering och sairbarhet—ansikte mot ansikte med Goffmans perspektiv på social interaktion (Ritualization and Vulnerability-Face to Face with Goffman's Perspective on Social Interaction). Malmö: Liber.

Pozner, J.-E. (2008) 'Stigma and settling up: An integrated approach to the consequences of organizational misconduct for organizational elites', Journal of Business Ethics 80: 141-150. doi: http://dx.doi.org/10.1007/s10551-007-9446-9.

Rehn, A. (2006) Företagsekonomin och "la trahison des clercs" (Business Studies and the Betrayal of the Intellectuals). Stockholm: Pink Machine Books.

Sutton, R.I. and Callahan, A.L. (1987) 'The stigma of bankruptcy: Spoiled organizational image and its management', Academy of Management Journal 30(3): 405-436. doi: http://dx.doi.org/10.2307/256007.

Van Maanen, J. (1979) 'The fact of fiction in organizational ethnography', Administrative Science Quarterly 24(4): 539-550.

Vergne, J.P. (2012) 'Stigmatized categories and public disapproval of organizations: A mixed-methods study of the global arms industry, 1996-2007', Academy of Management Journal 55(5): 1027-1052. doi: http://dx.doi.org/10.5465/amj.2010.0599.

Warren, D.E. (2007) 'Corporate scandals and spoiled identities: How organizations shift stigma to employees', Business Ethics Quarterly 17(3): 477-496. doi: http://dx.doi. org/10.5840/beq200717347.

Yakhlef, A. (2010) 'The corporeality of practice-based learning', Organization Studies 31(04): 409-430. doi: http://dx.doi.org/10.1177/0170840609357384.

Young, I.-M. (1994) 'Gender as seriality: Thinking about women as a social collective', Signs: Journal of Women in Culture and Society 19(3): 713-738. doi: http://dx.doi. org/10.1086/494918. 